\title{
Drug Holidays and Overall Survival of Patients with Metastatic Colorectal Cancer
}

\author{
Silvio Ken Garattini ${ }^{1, *}{ }^{\mathbb{D}}$, Debora Basile ${ }^{2}$, Marta Bonotto ${ }^{1}$, Elena Ongaro ${ }^{3}$, Luca Porcu ${ }^{4}$, Carla Corvaja ${ }^{5}$, \\ Monica Cattaneo ${ }^{5}$, Victoria Josephine Andreotti ${ }^{5}$, Camilla Lisanti ${ }^{5}$, Elisa Bertoli ${ }^{5}$, Giacomo Pelizzari ${ }^{1}{ }^{1}$, \\ Donatella Iacono $^{1}$, Gianmaria Miolo ${ }^{3}{ }^{\mathbb{D}}$, Giovanni Gerardo Cardellino ${ }^{1}$, Angela Buonadonna ${ }^{3}$, \\ Giuseppe Aprile ${ }^{2}$, Gianpiero Fasola ${ }^{1}$, Fabio Puglisi ${ }^{3,5}$ (D) and Nicoletta Pella ${ }^{1}$
}

1 Department of Oncology, ASUFC University Hospital of Udine, 33100 Udine, Italy; marta.bonotto@asufc.sanita.fvg.it (M.B.); giacomo.pelizzari@asufc.sanita.fvg.it (G.P.); donatella.iacono@asufc.sanita.fvg.it (D.I.); giovanni.cardellino@asufc.sanita.fvg.it (G.G.C.); gianpiero.fasola@asufc.sanita.fvg.it (G.F.); nicoletta.pella@asufc.sanita.fvg.it (N.P.)

2 Department of Oncology, San Bortolo General Hospital, 36100 Vicenza, Italy; deborabasile1090@gmail.com (D.B.); giuseppe.aprile@aulss8.veneto.it (G.A.)

3 Department of Medical Oncology, Unit of Medical Oncology and Cancer Prevention, Centro di Riferimento Oncologico di Aviano (CRO), IRCCS, 33081 Aviano, Italy; elena.ongaro@cro.it (E.O.); gmiolo@cro.it (G.M.); abuonadonna@cro.it (A.B.); fabio.puglisi@cro.it (F.P.)

4 Laboratory of Methodology for Clinical Research, Department of Oncology, Istituto di Ricerche Farmacologiche Mario Negri IRCCS, 20156 Milan, Italy; luca.porcu@marionegri.it

5 Department of Medicine, University of Udine, 33100 Udine, Italy; carlacorvaja@gmail.com (C.C.); aprile83@gmail.com (M.C.); victoriaja888@gmail.com (V.J.A.); drlisanti.camilla@gmail.com (C.L.); bertoli.eli@gmail.com (E.B.)

updates

Citation: Garattini, S.K.; Basile, D.; Bonotto, M.; Ongaro, E.; Porcu, L.; Corvaja, C.; Cattaneo, M.; Andreotti, V.J.; Lisanti, C.; Bertoli, E.; et al. Drug Holidays and Overall Survival of Patients with Metastatic Colorectal Cancer. Cancers 2021, 13, 3504. https://doi.org/10.3390/ cancers13143504

Academic Editor: Jesús García-Foncillas

Received: 20 May 2021

Accepted: 12 July 2021

Published: 13 July 2021

Publisher's Note: MDPI stays neutral with regard to jurisdictional claims in published maps and institutional affiliations.

Copyright: (c) 2021 by the authors. Licensee MDPI, Basel, Switzerland. This article is an open access article distributed under the terms and conditions of the Creative Commons Attribution (CC BY) license (https:/ / creativecommons.org/licenses/by/ $4.0 /)$.
* Correspondence: silvioken@hotmail.it; Tel.: +39-333-1335005; Fax: +39-0432-552751

Simple Summary: During first-line treatment of metastatic colorectal cancer, drug holidays (DHs) are usually adopted to limit toxicity. Literature lacks a formal demonstration that first-line continuous treatment, or maintenance, provides longer overall survival compared to DHs. We retrospectively studied the overall survival impact of DHs, demonstrating that a treatment break after initial induction chemotherapy may be considered in carefully clinically selected patients with metastatic colorectal cancer. Our study should reassure medical oncologists dedicated to colorectal cancer on the use of DHs.

Abstract: Different de-escalation strategies have been proposed to limit the risk of cumulative toxicity and guarantee quality of life during the treatment trajectory of patients with metastatic colorectal cancer (mCRC). Programmed treatment interruptions, defined as drug holidays (DHs), have been implemented in clinical practice. We evaluated the association between DHs and overall survival (OS). This was a retrospective study, conducted at the University Hospital of Udine and the IRCCS CRO of Aviano. We retrieved records of 608 consecutive patients treated for mCRC from 1 January 2005 to 15 March 2017 and evaluated the impact of different de-escalation strategies (maintenance, DHs, or both) on OS through uni- and multivariate Cox regression analyses. We also looked at attrition rates across treatment lines according to the chosen strategy. In our study, $19.24 \%$ of patients received maintenance therapy, $16.12 \%$ DHs, and $9.87 \%$ both, while $32.07 \%$ continued full-intensity first-line treatment up to progression or death. In uni- and multivariate analyses first-line continuous treatment and early discontinuation (treatment for less than 3 months) were associated to worse OS compared to non-continuous strategies (HR, 1.68; 95\% CI, 1.22-2.32; $p=0.002$ and HR,4.89; 95\% CI, 3.33-7.19; $p<0.001$, respectively). Attrition rates were $22.8 \%, 20.61 \%$, and $19.64 \%$ for maintenance, DHs, or both, respectively. For continuous therapy and for treatment of less than 3 months it was $21.57 \%$ and $49 \%$. De-escalation strategies are safe and effective options. DHs after initial induction chemotherapy may be considered in clinically selected patients with metastatic colorectal cancer.

Keywords: metastatic colorectal cancer; treatment strategies; drug holidays; maintenance 


\section{Introduction}

Colorectal cancer (CRC) is the third-most-common and the fourth-most-lethal cancer worldwide [1]. In a recent projection, CRC-related deaths are expected to rise over the next 15 years. However, mortality rates are predicted to continue to decrease globally [2], due to early detection and improvement of surgical and loco-regional techniques in the metastatic setting [3]. Furthermore, the development of new chemotherapy combination regimens and the introduction of biologic agents in recent decades has also led to a further increase in survival [4-9]. Consequently, clinicians need to manage patient treatment for up to two to three years and to define sequences and durations of the treatments, avoiding a heavy treatment burden and controlling long term toxicities. Thus, various groups started to investigate milder therapeutic approaches introducing maintenances (interruption of a part of the upfront chemotherapy backbone), intermittent strategies (on/off treatment periods for preplanned times), and treatment-free drug holidays (DHs) in patients who have obtained disease control with induction combination chemotherapy.

Historically, discontinuation of oxaliplatin has been the first attempt to limit doserelated neurotoxicity, thus representing the paradigm of de-escalation to maintenance therapy. Different trials successfully evaluated oxaliplatin omission after doublet or triplet induction chemotherapy, with or without biologic agents, and "stop-and-go" approaches [10-12]. Maintenance therapy with fluoropyrimidines, combined or not to bevacizumab or anti-EGFR, may effectively reduce toxicities and improve patients' quality of life without compromising clinical outcomes [13-15]. Unfortunately, maintenance with biological agents only [15-18] has not been successful so far. Maintenance treatment with a biological agent (i.e., bevacizumab) versus a drug holiday $(\mathrm{DH})$ approach $[19,20]$ led to interesting results. Several studies compared biologic drugs and/or fluoropyrimidine full-intensity (or maintenance therapy) with DHs, with contrasting results in terms of overall survival [20-22]. Moreover, the recent introduction of more intense chemotherapy regimens has led to higher response rates (RR) and more profound responses that generate longer progression-free survival (PFS) making clinicians more prone to offer DHs [23,24]. As no conclusive results on the overall survival (OS) benefit of continuous chemotherapy over maintenance or DHs have been achieved so far, the aim of this study is to evaluate the impact of de-escalation strategies (maintenance and, with special interest, DHs) on OS compared to continuous treatment.

\section{Results}

\subsection{Descriptive Analysis}

The study included a cohort of 890 patients with a diagnosis of mCRC who received at least a first-line chemotherapy regimen. The final analysis was, however, performed on a population of 608 patients who had not received metastasectomies or loco-regional treatments within first-line treatment (clinical, pathological, and treatment characteristics are listed in Table 1 ). In the whole cohort, $64.14 \%$ of the patients were younger than 70 years. Of note, $28.95 \%$ had a right tumor location and $72.86 \%$ underwent surgery on the primary tumor. Approximately $40 \%$ had more than one metastatic site involved and the most frequent site of metastatic spread was the liver (33.55\%), followed by the lungs $(21.05 \%)$, peritoneum $(20.23 \%)$, and lymph nodes $(16.78 \%)$. A metastasectomy before first-line chemotherapy was performed in $21.05 \%$ of the whole cohort. As for the biological profile, KRAS, NRAS, and BRAF mutations were detected in $38.98 \%, 2.63 \%$, and $7.40 \%$ of patients, respectively. First-line chemotherapy consisted of a combination of a triplet plus a biologic agent in $9.38 \%$ of cases, whereas $75.79 \%$ received a doublet-based regimen (approximately $44 \%$ doublet plus biologic agent and 31\% doublet alone). After induction chemotherapy, treatment strategies included maintenance therapy in $19.24 \%$ of patients, a drug holiday in $16.12 \%$, or both in $9.87 \%$. Of note, $16.78 \%$ received first-line chemotherapy for less than 3 months overall. A second-line chemotherapy regimen was offered to $69.41 \%$ of the patients. 
Table 1. Demographic and clinical characteristics of the patients at baseline. Frequencies of variables are reported by absolute number and by percentage value.

\begin{tabular}{|c|c|c|}
\hline Characteristic & N Total (608 Patients) & Frequency $(\%)$ \\
\hline \multicolumn{3}{|l|}{ Sex: } \\
\hline Male & 383 & $63.0 \%$ \\
\hline Female & 225 & $37.0 \%$ \\
\hline \multicolumn{3}{|l|}{ Age: } \\
\hline$<70$ & 390 & $64.14 \%$ \\
\hline$>70$ & 218 & $35.86 \%$ \\
\hline \multicolumn{3}{|l|}{ ECOG performance status: } \\
\hline 0 & 51 & $8.39 \%$ \\
\hline 1 & 463 & $76.15 \%$ \\
\hline 2 & 48 & $7.89 \%$ \\
\hline Missing & 46 & $7.57 \%$ \\
\hline \multicolumn{3}{|l|}{ Location of primary tumor: } \\
\hline Right & 176 & $28.95 \%$ \\
\hline Left & 245 & $40.30 \%$ \\
\hline Rectum & 181 & $29.77 \%$ \\
\hline Missing & 6 & $0.99 \%$ \\
\hline \multicolumn{3}{|l|}{ Pathological T stage (TNM): } \\
\hline pT1 & 7 & $1.15 \%$ \\
\hline pT2 & 31 & $5.10 \%$ \\
\hline pT3 & 281 & $46.22 \%$ \\
\hline PT4 & 117 & $19.24 \%$ \\
\hline Missing & 172 & $28.30 \%$ \\
\hline \multicolumn{3}{|l|}{ Pathological N stage (TNM): } \\
\hline N0 & 107 & $17.60 \%$ \\
\hline N1 & 142 & $23.36 \%$ \\
\hline N2 & 172 & $28.95 \%$ \\
\hline N3 & 55 & $9.05 \%$ \\
\hline Missing & 132 & $21.71 \%$ \\
\hline \multicolumn{3}{|l|}{ Tumor Grading: } \\
\hline G1-2 & 244 & $40.13 \%$ \\
\hline G3-4 & 156 & $26.66 \%$ \\
\hline Missing & 208 & $34.21 \%$ \\
\hline \multicolumn{3}{|l|}{ Resection of primary tumor: } \\
\hline Yes & 443 & $72.86 \%$ \\
\hline No & 161 & $26.48 \%$ \\
\hline Missing & 4 & $0.66 \%$ \\
\hline \multicolumn{3}{|l|}{ Adjuvant chemotherapy: } \\
\hline Yes & 87 & $14.31 \%$ \\
\hline No & 362 & $26.48 \%$ \\
\hline N.A. & 159 & $26.15 \%$ \\
\hline \multicolumn{3}{|l|}{ Neoadjuvant chemotherapy and RT: } \\
\hline Yes & 76 & $12.50 \%$ \\
\hline No & 509 & $83.72 \%$ \\
\hline Missing & 23 & $3.78 \%$ \\
\hline \multicolumn{3}{|c|}{ Metastasectomy before first-line chemotherapy: } \\
\hline Yes & 128 & $21.05 \%$ \\
\hline No & 478 & $78.62 \%$ \\
\hline Missing & 2 & $0.33 \%$ \\
\hline
\end{tabular}


Table 1. Cont.

\begin{tabular}{|c|c|c|}
\hline Characteristic & N Total (608 Patients) & Frequency $(\%)$ \\
\hline \multicolumn{3}{|l|}{ Number of metastatic sites: } \\
\hline 1 & 352 & $57.89 \%$ \\
\hline$>1$ & 240 & $39.47 \%$ \\
\hline Missing & 16 & $2.63 \%$ \\
\hline \multicolumn{3}{|l|}{ Metastatic sites: } \\
\hline Liver & 204 & $33.55 \%$ \\
\hline Lung & 128 & $21.05 \%$ \\
\hline Lymph nodes & 102 & $16.78 \%$ \\
\hline Peritoneum & 123 & $20.23 \%$ \\
\hline Bone & 12 & $1.97 \%$ \\
\hline CNS & 6 & $0.99 \%$ \\
\hline Missing & 33 & $5.43 \%$ \\
\hline \multicolumn{3}{|l|}{ Histotype: } \\
\hline Mucinous & 72 & $11.84 \%$ \\
\hline Not mucinous & 324 & $53.29 \%$ \\
\hline Missing & 212 & $34.87 \%$ \\
\hline \multicolumn{3}{|l|}{ First-line chemotherapy: } \\
\hline Single agent & 72 & $11.84 \%$ \\
\hline Doublet & 191 & $31.41 \%$ \\
\hline Doublet + biologic agent & 270 & $44.41 \%$ \\
\hline Triplet + biologic agent & 57 & $9.38 \%$ \\
\hline Other & 18 & $2.96 \%$ \\
\hline \multicolumn{3}{|c|}{$\begin{array}{l}\text { Maintenance therapy or drug holiday within } \\
\text { first-line: }\end{array}$} \\
\hline Maintenance & 117 & $19.24 \%$ \\
\hline Holiday & 98 & $16.12 \%$ \\
\hline Maintenance and holiday & 60 & $9.87 \%$ \\
\hline Continuous treatment & 195 & $32.07 \%$ \\
\hline$<3$ months of chemotherapy & 102 & $16.78 \%$ \\
\hline Missing & 36 & $5.92 \%$ \\
\hline \multicolumn{3}{|l|}{ Molecular biology status: } \\
\hline BRAF mut. & 45 & $7.40 \%$ \\
\hline BRAF unknown & 131 & $21.55 \%$ \\
\hline KRAS mut. & 237 & $38.98 \%$ \\
\hline KRAS unknown & 93 & $15.30 \%$ \\
\hline NRAS mut. & 16 & $2.63 \%$ \\
\hline NRAS unknown & 192 & $31.58 \%$ \\
\hline All-RAS mut. & 295 & $48.5 \%$ \\
\hline All-RAS unknown & 62 & $10.2 \%$ \\
\hline \multicolumn{3}{|l|}{ Second-line chemotherapy: } \\
\hline Yes & 422 & $69.41 \%$ \\
\hline No & 161 & $26.48 \%$ \\
\hline Missing & 25 & $4.11 \%$ \\
\hline \multicolumn{3}{|l|}{ Drug Holiday: } \\
\hline Yes & 156 & $26.7 \%$ \\
\hline No & 421 & $69.2 \%$ \\
\hline Missing & 31 & $5.1 \%$ \\
\hline \multicolumn{3}{|l|}{ Motivation for DH: } \\
\hline Patient's request & 17 & $10.9 \%$ \\
\hline Physician-patient shared choice & 103 & $66.0 \%$ \\
\hline Unacceptable toxicity & 29 & $18.6 \%$ \\
\hline Missing & 7 & $4.5 \%$ \\
\hline
\end{tabular}




\subsection{Survival Impact of De-Escalation Strategies}

At the median follow-up of 70.32 months, median OS was 20.25 months. At univariate analysis for OS (Table 2), all-RAS mutations (HR, 1.38; 95\% CI, 1.14-1.66; $p=0.001$ ), ECOG performance status of 1 or 2 ( 1 vs. $0 \mathrm{HR}, 1.99$; 95\% CI, 1.39-2.85; $p=0.000$; 2 vs. $0 \mathrm{HR}, 3.44$; 95\% CI, 2.18-5.44; $p<0.001$, respectively), and number of metastatic sites $>1$ (HR, 1.40; $95 \%$ CI $1.16-1.67 ; p<0.001$ ) were associated with worse prognosis, as well as the extent of lymph nodes involvement, both for N2 (HR, 1.56; 95\% CI, 1.19-2.05; $p=0.001)$ and N3 tumors (HR, 2.31; 95\% CI, 1.61-3.30; $p<0.001)$. According to treatment execution after induction therapy, worse outcomes were observed for patients who had continuous combination chemotherapy without maintenance or drug holidays (HR, 1.57; 95\% CI, 1.22-2.02; $p=0.001)$ and for those who had received chemotherapy for less than 3 months (HR, 3.75; 95\% CI, 2.81-5.01; $p<0.001$ ) (Figure 1). Median OS was 25.05, 29.79, and 30.25 months, respectively, in patients who had received maintenance therapy, drug holidays, or both (Figure 1). For patients who had continuous combination chemotherapy and those who had received chemotherapy for less than 3 months, median OS was 17.23 and 7.82 months, respectively. Conversely, left sidedness and rectum disease (HR, 0.66; 95\% CI, 0.54-0.82; $p<0.001$ and $\mathrm{HR}, 0.64 ; 95 \% \mathrm{CI}, 0.51-0.81 ; p=0.000$, respectively), primary tumor resection (HR, $0.47 ; 95 \% \mathrm{CI}, 0.39-0.58 ; p<0.001)$ and metastasectomy before first-line chemotherapy (HR, 0.73; 95\% CI, 0.59-0.91; $p=0.005)$ were associated with better OS (Table 2). Multivariate analysis for OS, left sidedness, and rectum disease confirmed to be independent prognostic factors of favorable survival outcomes (HR, 0.59; 95\% CI, $0.45-0.79 ; p<0.001$ and HR, 0.56; 95\% CI 0.41-0.77; $p<0.001$, respectively). Moreover, the extent of nodal disease N2 (HR, 1.57; 95\% CI, 1.14-2.17; $p=0.005)$ and a PS ECOG of 1 (HR, 2.48; 95\% CI, $1.67-3.76 ; p<0.001)$ confirmed independent unfavorable prognostic factors. Interestingly, a worse prognosis was confirmed for patients who had not been offered maintenance therapy or drug holidays and for those who were exposed to chemotherapy for less than 3 months (HR, 1.68; 95\% CI, 1.22-2.32; $p=0.002$ and HR, 4.89; 95\% CI, 3.33-7.19; $p<0.001$, respectively) (Table 2 ).

Table 2. Univariate and multivariate analyses for OS. Significant associations are written in bold.

\begin{tabular}{|c|c|c|c|c|c|c|}
\hline \multirow[b]{2}{*}{ Variables } & \multicolumn{3}{|c|}{ Univariate Analysis } & \multicolumn{3}{|c|}{ Multivariate Analysis } \\
\hline & HR & $p$ & $95 \%$ CI & HR & $p$ & $95 \% \mathrm{CI}$ \\
\hline \multicolumn{7}{|l|}{ Location of primary tumor: } \\
\hline Right & 1.00 & & & & & \\
\hline Left & 0.66 & $<0.001$ & $0.54-0.82$ & 0.59 & $<0.001$ & $0.45-0.79$ \\
\hline Rectum & 0.64 & $<0.001$ & $0.51-0.81$ & 0.56 & $<0.001$ & $0.41-0.77$ \\
\hline \multicolumn{7}{|l|}{ Resection of primary tumor: } \\
\hline No & 1.00 & & & & & \\
\hline Yes & 0.47 & $<0.001$ & $0.39-0.58$ & 1.37 & 0.17 & $0.87-2.17$ \\
\hline \multicolumn{7}{|l|}{ Grading: } \\
\hline G1-2 & 1.00 & & & & & \\
\hline G3-4 & 1.07 & 0.552 & $0.86-1.33$ & & & \\
\hline \multicolumn{7}{|l|}{ Nodes: } \\
\hline 0 & 1.00 & & & & & \\
\hline 1 & 1.16 & 0.304 & $0.87-1.55$ & 1.04 & 0.784 & $0.75-1.46$ \\
\hline 2 & 1.56 & 0.001 & $1.19-2.05$ & 1.57 & 0.005 & $1.14-2.17$ \\
\hline 3 & 2.31 & $<0.001$ & $1.61-3.30$ & 1.52 & 0.129 & $0.88-2.63$ \\
\hline \multicolumn{7}{|l|}{ Adjuvant chemotherapy: } \\
\hline No & 1.00 & & & & & \\
\hline Yes & 1.02 & 0.888 & $0.78-1.34$ & & & \\
\hline \multicolumn{7}{|l|}{ All-RAS: } \\
\hline wt & 1.00 & & & & & \\
\hline mut & 1.38 & 0.001 & $1.14-1.66$ & 1.07 & 0.572 & $0.84-1.36$ \\
\hline
\end{tabular}


Table 2. Cont.

\begin{tabular}{|c|c|c|c|c|c|c|}
\hline & \multicolumn{3}{|c|}{ Univariate Analysis } & \multicolumn{3}{|c|}{ Multivariate Analysis } \\
\hline \multicolumn{7}{|l|}{ ECOG performance status: } \\
\hline 0 & 1.00 & & & & & \\
\hline 1 & 1.99 & $<0.001$ & $1.39-2.85$ & 2.48 & $<0.001$ & $1.67-3.76$ \\
\hline 2 & 3.44 & $<0.001$ & $2.18-5.44$ & 1.67 & 0.083 & $0.93-3.00$ \\
\hline \multicolumn{7}{|l|}{ Number of metastatic sites: } \\
\hline$<1$ & 1.00 & & & & & \\
\hline$>1$ & 1.40 & $<0.001$ & $1.16-1.67$ & 1.19 & 0.155 & $0.93-1.52$ \\
\hline \multicolumn{7}{|l|}{ Metastasectomy before first-line: } \\
\hline No & 1.00 & & & & & \\
\hline Yes & 0.73 & 0.005 & $0.59-0.91$ & 0.86 & 0.291 & $0.66-1.13$ \\
\hline \multicolumn{7}{|l|}{ Treatment strategy after induction: } \\
\hline Maintenance & 1.00 & - & - & 1.00 & - & - \\
\hline Holiday & 0.76 & 0.12 & $0.59-1.07$ & 0.94 & 0.758 & $0.66-1.35$ \\
\hline Maintenance and holiday & 0.78 & 0.137 & $0.55-1.10$ & 0.70 & 0.108 & $0.46-1.08$ \\
\hline Continuous treatment & 1.57 & 0.001 & $1.22-2.02$ & 1.68 & 0.002 & $1.22-2.32$ \\
\hline$<3$ months of chemotherapy & 3.75 & $<0.001$ & $2.81-5.01$ & 4.89 & $<0.001$ & $3.33-7.19$ \\
\hline
\end{tabular}

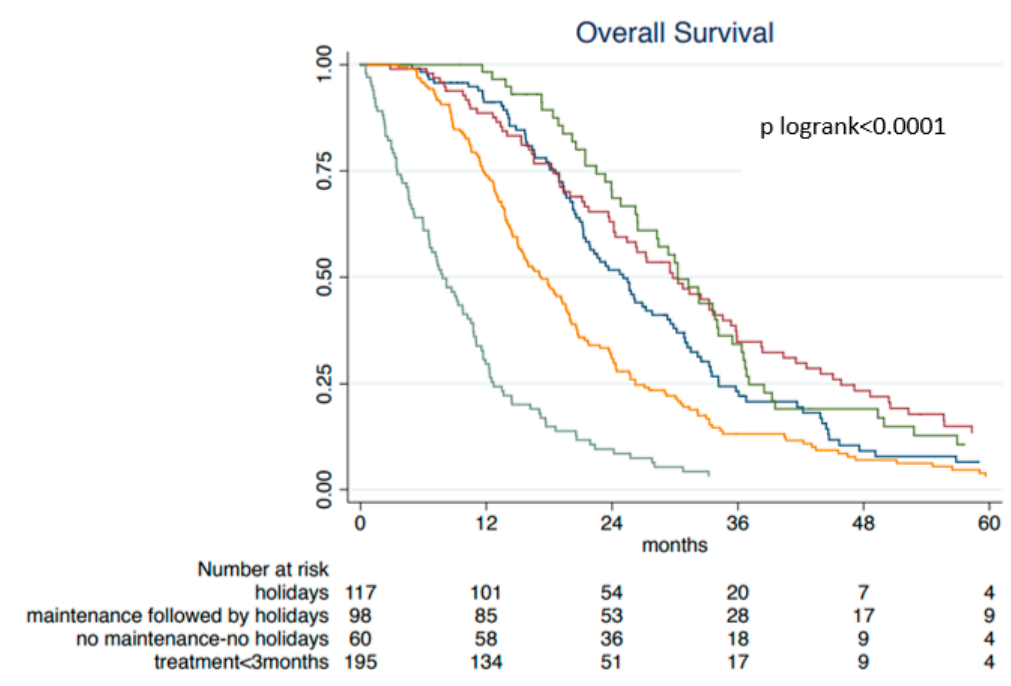

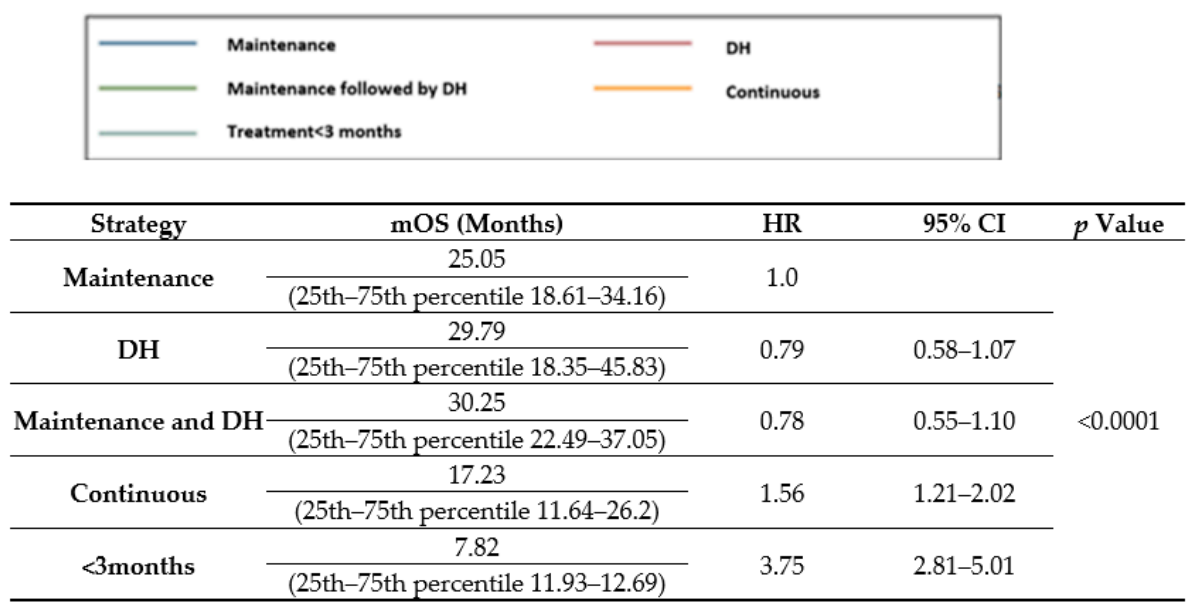

Figure 1. Kaplan-Meier survival curves according to strategy. 
An ROC analysis was performed to develop a prognostic scoring model, based on selected factors that emerged in the multivariate analysis (every negative prognostic factor received a weighed score). The prognostic score aimed at identifying a threshold to discriminate patients with good and poor prognosis (Table 3). The cutoff identified was as score of 3 with higher than 3 predicting worse OS (Figure S1). Analyzing only the cohort of patients with a score $<3$ (good prognosis group), maintenance, holidays, or both did not show a significantly worse prognosis (HR, $0.75 ; 95 \% \mathrm{CI}, 0.53-1.07 ; p=0.112$ and $\mathrm{HR}$, $0.79 ; 95 \%$ CI, $0.53-1.17 ; p=0.254$, respectively). Obviously, the continuous chemotherapy (HR, 1.63; 95\% CI, 1.22-2.19; $p=0.001$ ) and a treatment duration less than 3 months $(\mathrm{HR}, 3.34 ; 95 \% \mathrm{CI}, 2.36-4.73 ; p<0.001)$ were associated with a worse outcome (Figure 2$)$.

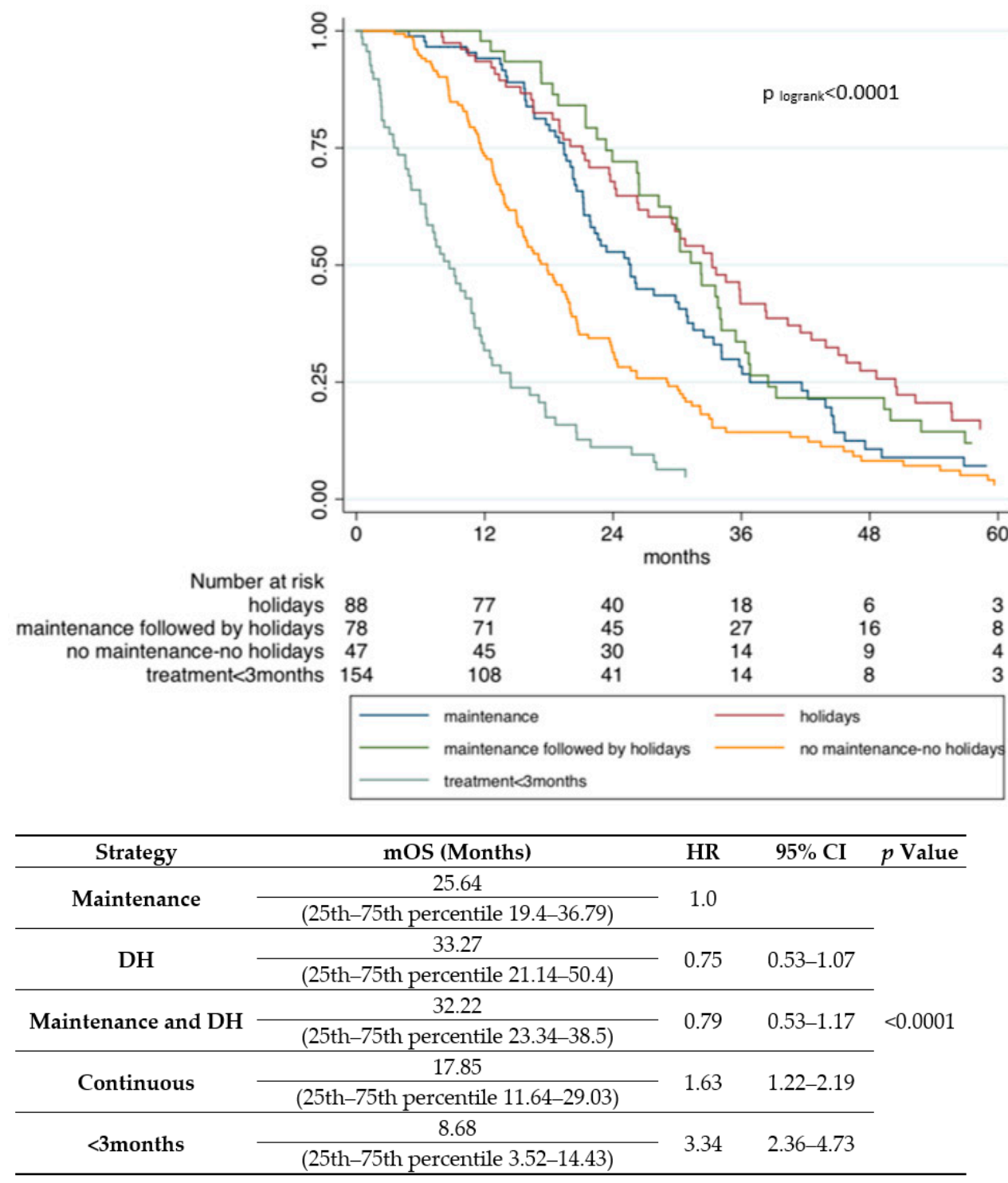

Figure 2. Kaplan-Meier survival curves according to strategy in patients with score $<3$. 
Table 3. Multivariate model for prognostic factors and Score construction. Significant associations are written in bold.

\begin{tabular}{lcccc}
\hline \multicolumn{1}{c}{ Variables } & \multicolumn{3}{c}{ Multivariate Analysis } & Score (Points) \\
\hline \multicolumn{1}{c}{ HR } & $p$ & $\mathbf{9 5} \%$ CI & \\
\hline Right location of primary tumor & $\mathbf{1 . 5 7}$ & $<\mathbf{0 . 0 0 1}$ & $\mathbf{1 . 2 5}-\mathbf{1 . 9 7}$ & $\mathbf{1}$ \\
\hline All-RAS mutated & 1.26 & 0.189 & $0.89-1.78$ & \\
\hline ECOG performance status: & & & & \\
1 & $\mathbf{1 . 8 1}$ & $\mathbf{0 . 0 1 0}$ & $\mathbf{1 . 1 5 - 2 . 8 4}$ & $\mathbf{1}$ \\
\multicolumn{1}{c}{$\mathbf{2 . 5 8}$} & $\mathbf{0 . 0 0 1}$ & $\mathbf{1 . 4 8 - 4 . 5 1}$ & $\mathbf{2}$ \\
\hline Metastatic sites $>1$ & 1.17 & 0.179 & $0.93-1.46$ & \\
\hline Metastasectomy & 0.95 & 0.703 & $0.73-1.24$ & \\
\hline Primary tumor unresected & $\mathbf{1 . 7 2}$ & $<\mathbf{0 . 0 0 1}$ & $\mathbf{1 . 3 3 - 2 . 2 2}$ & $\mathbf{1}$ \\
\hline
\end{tabular}

\subsection{Attrition Rate across First-Line Treatment Strategies}

In the overall population, the attrition rate (percentage of patients not achieving a further line of treatment) between first- and second-line chemotherapy was $27.62 \%$. In particular, the attrition rate was $22.80 \%, 20.61 \%$, and $19.64 \%$ for patients who had received maintenance therapy, drug holidays, or both, whereas attrition rates of $21.57 \%$ and $49 \%$, respectively, were observed in the subgroups of patients who had continuous combination chemotherapy and those who had received chemotherapy for less than 3 months $(p<0.0001)$ (Figure 3). We looked for an association between de-potentiation strategies (DHs, maintenance, or both) and re-induction and we found it statistically significant $(p=0.012)$. The strongest association was between maintenance plus DHs and re-induction, followed by maintenance and then by DHs alone.

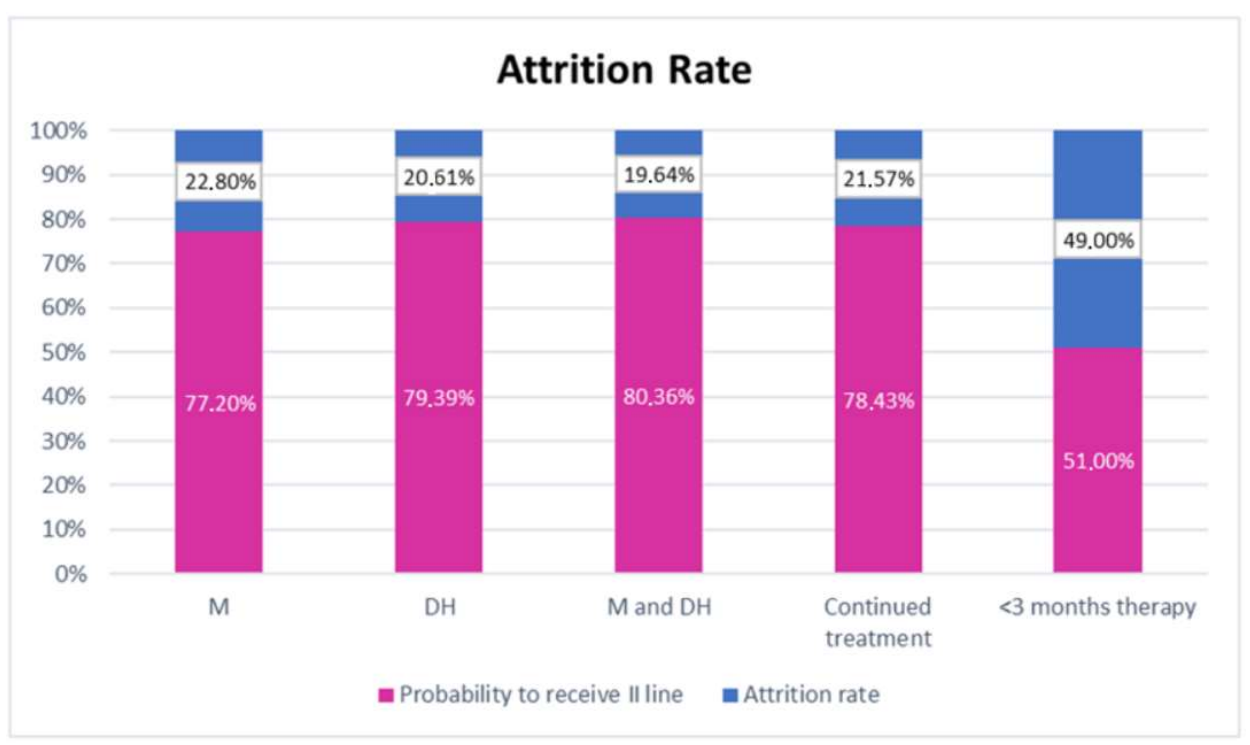

Figure 3. Attrition rate and probability of receiving II line treatment. M: maintenance; DH: drug holidays; $\mathrm{M}$ and DH: maintenance and drug holidays.

\section{Discussion}

Advances in molecular biology and the introduction of novel therapeutic agents in $\mathrm{mCRC}$ treatment has led to significant improvement in survival, bringing the median OS up to about 30 months [25].

Though treatment de-escalation strategies are usually part of the treatment strategy used by medical oncologists in daily clinical practice, literature lacks a substantial formal demonstration of the efficacy of these approaches, especially if compared to continuous 
strategies. In a previous study, our group analyzed the use of DHs in a real world setting along with clinical and pathological factors associated with the choice of offering a DH [26].

The present study aimed to demonstrate the impact of de-escalation algorithms (with a special focus on DHs) on survival outcomes and whether these strategies resulted in detrimental survival in 608 consecutive mCRC patients. Maintenance treatment, drug holidays, maintenance followed by a break, and continuous treatment were analyzed in this study.

First, our real-world data confirmed that treatment de-escalation is a common practice. Indeed, $19.24 \%, 16.12 \%$, and $9.87 \%$ of patients received maintenance, treatment holidays, or both, with the total percentage of de-escalated treatments reaching $45.23 \%$ in almost half of the cases.

Second, de-escalated treatment was associated with better OS compared to the continuous combination chemotherapy (HR, 1.68 for continuous treatment and HR, 4.89 for treatment $<3$ months), fostering shared decision-making of de-escalating strategies in daily clinical practice in carefully selected patients.

Evidence supporting de-escalating strategies is mostly derived from prospective studies. The UK MRCCR06 trial, the first assessing treatment holidays in patients with $\mathrm{mCRC}$ with stable or responding disease after 12 weeks of chemotherapy, detected fewer adverse events and no difference in terms of OS between continuous and intermittent treatment (HR, 0.87; 95\% CI, 0.69-1.09; $p=0.23)$ [27]. In the GISCAD trial, an intermittent schedule of 5-fluorouracil plus irinotecan administered 2-months-on and 2-months-off showed equivalent progression-free survival (PFS) (HR, 1.03; 95\% CI, 0.81-1.29) and OS (HR, 0.88; 95\% CI, 0.69-1.14) compared to treatment continuation [28]. Conversely, the MRC COIN trial failed to meet the non-inferiority of drug holidays after 5-fluorouracil plus oxaliplatin (OS: HR, 1.08; 95\% CI, 0.97-1.21 and PFS: HR, 1.05; 95\% CI, 0.95-1.17) [29]. Survival outcomes of maintenance treatment were examined in the OPTIMOX1 study. FOLFOX followed by 5-fluorouracil produced similar efficacy compared to continuous FOLFOX (PFS: HR, 1.06; 95\% CI, 0.89-1.20; $p=0.47$ and OS: HR, 0.93; 95\% CI, 0.72-1.11; $p=0.49)[10]$.

As to chemotherapy-free intervals (CFI), the conclusions of the OPTIMOX2, CAIRO3, and AIO-027 trials reported improvement in terms of survival in favor of the maintenance strategy compared to treatment holidays [16,22,30]. However the meta-analysis of Berry et al. evaluated 11 randomized clinical trials including OPTIMOX2, CAIRO3, and AIO-027 trials and reported no clinically significant reduction of OS between intermittent and continuous strategies (HR, 1.03; 95\% CI, 0.96-1.10; $p=0.38$ ) [31]. Lorée et al. also showed, in a retrospective study, that patients undergoing any de-escalation had better OS than the ones continuing a full-intensity regimen [32].Likewise in our analysis patients receiving DHs or maintenance plus DHs had similar OS ( $p=0.461$, holidays; $p=0.080$, holidays and maintenance, taking maintenance as reference), even after correction for confounding variables.

Summing up, although treatment maintenance showed improved PFS over chemotherapy-free intervals, noteworthy treatment holidays improved QoL in some trial, as reported in CAIRO-3 [22]. Similarly, MRC COIN demonstrated that delivering systemic chemotherapy in first-line followed by a treatment break improved social (OR, 0.82; 95\% CI, $0.70-0.96 ; \mathrm{p}=0.016)$ and role functioning (OR, 0.82; 95\% CI, 0.70-0.96; $\mathrm{p}=0.015)$ compared to maintenance therapy [29]. A key difference of our study compared to the aforementioned trials is that the latter were conceived with rigid protocols imposing (since the time of randomization) the type of de-escalation after a pre-established number of cycles and did not allow adaptation of the execution on the basis of the type of response. None of the prospective studies allowed both maintenance and intermittent therapy, whereas our series also included patients treated with a sequence of intermittent and maintenance chemotherapy. Of note, we reported similar survival outcomes for both patients treated with maintenance only and with maintenance followed by a break. 
Since losing the chance to access a second-line treatment could be considered a risky collaterality of de-escalation strategies, we also analyzed this aspect. In our study, the whole population attrition rate was $27 \%$, consistent with previous literature data [33]. The attrition rate between first- and second-line treatment was $22.80 \%, 20.61 \%$, and $19.64 \%$ for maintenance, a break, or both. This is reassuring, considering that attrition plays a key role in $\mathrm{mCRC}$ and it can hinder the benefits in terms of OS of a sequential treatment strategy. In our study, $25 \%$ of patients undergoing holidays from toxicities did not receive second-line treatment compared to $19 \%$ of patients performing holidays by the physician's choice. This was not the case for the "early discontinuators" (mostly patients whose disease progression occurred within three months from the beginning first-line treatment). Indeed, the attrition rate was $49 \%$ in this group.

We speculated that better OS in de-escalation strategies (over continuous) could be driven by a selection bias. If physicians had offered de-escalation only to the best responders to first-line treatment or to patients with a lower burden of disease, then we could perform further analysis comparing the same treatment strategies only in the goodprognosis population. Patients with a score of $\geq 3$ (worst prognosis) were excluded and no differences were observed amongst good prognosis patients receiving maintenance, a break, or both, while a worse outcome was seen for continuous treatment. Anyway, even if not statistically significant, in this subgroup, treatment holidays could be considered one of the main options to be offered, as it demonstrates a numerically greater advantage (HR, $0.75 ; 95 \%$ CI, 0.53-1.06) in terms of OS.

We are aware that this was a retrospective analysis conducted in two centers of a limited geographic area and that the study did not provide data on QoL, that could have even more supported the advantages of DHs; finally, the reasons for starting maintenance treatment are lacking. Nevertheless, some precautions were taken by the authors to overcome the weaknesses of the study: first, metastatic patients receiving metastasectomy or loco-regional treatment during first-line therapy were excluded and second, patients were stratified based on the classical groups taken into consideration in clinical trials as well as on further groups to better stratify population. In sum, even though this study embodies both weaknesses and strengths of a "real world" analysis, compared to previous data from prospective trials, it is, to the best of our knowledge, the first study evaluating the OS impact and attrition rates of different de-potentiating strategies in a "real world" setting of mCRCs. Third, a little innovation of this study was the attempt to produce a score created in order to better select patients who could safely undergo de-escalation (both maintenance and, more innovatively, DHs). Finally, these results should be considered as "hypothesis generating" in order to investigate DHs in larger future studies.

\section{Materials and Methods}

\subsection{Study Design}

This was a bi-centric, observational, retrospective, cohort study that examined data on 890 consecutive metastatic colorectal cancer (mCRC) patients who underwent first-line chemotherapy. A cohort of 608 patients selected according to inclusion and exclusion criteria entered in the final analysis. The study aimed to evaluate the impact of different treatment strategies, after induction chemotherapy, in terms of overall survival (OS). Moreover, we analyzed attrition rates according to treatment algorithms and the impact of these strategies in a population selected for good prognosis. The study was conducted in accordance with the Declaration of Helsinki, and the protocol was approved by the departmental review boards and by the Ethic Committee (Parere CEUR-2019-Os-030, Regional Ethics Committee of Friuli Venezia Giulia, Italy).

\subsection{Patient Population}

We collected the clinical data of 608 consecutive patients. All patients had confirmed histological diagnosis of $\mathrm{mCRC}$ and provided consent to the use of clinical data, rendered anonymous, for purposes of clinical research, epidemiology, training, and study of diseases. 
The cohort consisted of consecutive patients treated at the Oncology Department of the University Hospital of Udine and the Medical Oncology and Cancer Prevention Unit of the CRO National Cancer Institute of Aviano (Italy) from 1 January 2005 and 15 March 2017. Data were retrieved from an electronic and paper-based medical chart review according to strict privacy standards.

Main inclusion criteria were: age $\geq 18$, histologically confirmed diagnosis of mCRC, having been treated with at least one line of chemotherapy. Data concerning age, sidedness, resection of primary tumor, date of metastatic disease diagnosis, pattern of metastasis, number of metastatic sites, molecular profile (KRAS, NRAS, BRAF, and all-RAS mutational status), date and type (single agent, single agent plus biologic, doublet, doublet plus biologic, triplet, triplet plus biologic, or other) of first-line chemotherapy, treatment strategy after induction therapy, metastasectomies and loco-regional therapies, and reasons for a treatment break and reinduction were collected. Finally, 608 patients were fully eligible (see CONSORTdiagram) and patients receiving metastasectomies and loco-regional therapies during first-line were excluded.

\subsection{Definition of Drug Holiday and Treatment Strategies}

Drug holidays, were defined as a treatment break of $\geq 56$ consecutive days free from any oncology treatment after a first-line "induction" therapy. This number of minimal days was defined on the basis of the previous study by Labianca et al. [28] This period of days was considered more in line with clinical practice than other definitions of a break [32]. Maintenance chemotherapy was defined as the omission of one or more agents (i.e., oxaliplatin/irinotecan) in patients that had previously received at least one cycle of combination treatment (doublet or triplet). Treatment after induction chemotherapy was categorized into DHs, maintenance, or both combined (maintenance first, DHs later) and compared with continuous full-intensity first-line therapy. Finally, to overcome potential selection bias, a fifth group, including patients receiving less than 3 months of induction therapy (early discontinuation) were individuated.

\subsection{Sample Size Calculation}

The sample size was estimated in order to obtain a good performance of the statistical model for the association between patient and tumor characteristics with outcome measures in the multivariate analysis. The aim of the sampling was the achievement of a good "goodness of fit" for the regression model according to Peduzzi et al. [34] They showed that for number of events per variable (EPV) values of 10 or more, no major problems occurred. In particular, 20-50 events per variable (EPV) would remove the need for shrinkage of estimated regression coefficients in prespecified models.

Therefore, according this evidence, considering 50 EPV and a final model with a maximum of nine variables, it would be necessary to have 450 events. By predicting that $80 \%$ of patients will have had an unfavorable outcome at the time of the analysis (estimating a median follow-up of about 6 years, in temporal terms), and considering a final model with nine variables, it would be necessary to enroll at least 563 patients to have 450 events. This number of patients is compatible with the epidemiological data relating to these centers within the set time limits. Therefore, we could define an accurate estimation for the multivariate model.

\subsection{Statistical Analysis}

Patients' clinical and pathological characteristics were summarized through descriptive analysis. Categorical variables were described with frequency distribution, whereas continuous variables were reported by median and range. Differences across groups were compared with the chi-square test for categorical variables. Patients alive at the time of last follow-up were censored.

For overall survival analyses, time at risk was calculated from the date of metastatic disease diagnosis to the date of the event of interest-death or last follow-up. For univariate 
survival analysis, OS probabilities were estimated using the Kaplan-Meier method and compared by log-rank test.

A Cox proportional-hazards regression model, also including potential confounders (e.g., age, biological profile, and sidedness) was used to calculate hazard ratios (HRs) of death, with the corresponding 95\% confidence intervals (CIs), among different subgroups of patients identified by type of treatment execution. In order to define the impact of treatment executions in patients with a good prognosis, a prognostic score model based on multivariate analysis was developed. To identify a threshold to discriminate patients with good and poor prognosis, a receiving operator curve (ROC) analysis was performed. Associations between variables were explored in the whole cohort by using statistical tests (chi-square, Wilcoxon rank-sum test, or Kruskal-Wallis test), as appropriate.

Overall survival (OS) was defined as the time between treatment start and death from any cause. Attrition rate was defined as the proportion of patients who started therapy but were not further treated at the time of disease progression due to progression itself or death, toxicity, or patient or physician decision; patients lost at follow-up were excluded from this analysis. A two-sided $p<0.05$ was considered statistically significant.

The data analysis was generated using STATA (StataCorp. (2015) Stata Statistical Software: Release 14.2. StataCorp LP, College Station, TX, USA).

\section{Conclusions}

In conclusion, our study supports the use of maintenance and DHs in a real-world cohort, ultimately demonstrating that physicians are able to carefully identify patients who may receive de-escalation without compromising their clinical outcomes.

Supplementary Materials: The following are available online at https:/ / www.mdpi.com/article/10 .3390 / cancers13143504/s1, Figure S1: Kaplan-Meier survival curves according to cut-off.

Author Contributions: Conceptualization, S.K.G., D.B., M.B., E.O., L.P., and N.P.; methodology, S.K.G., D.B., N.P., and G.A.; software, D.B.; validation, S.K.G. and D.B.; formal analysis, D.B.; data curation, S.K.G., D.B., C.C., M.C., V.J.A., C.L., E.B., G.P., and D.I.; writing-original draft preparation, S.K.G. and D.B.; writing—review, editing, visualization, and supervision, G.M., G.G.C., A.B., G.A., G.F., F.P., and N.P. All authors have read and agreed to the published version of the manuscript.

Funding: This research received no external funding.

Institutional Review Board Statement: The study was conducted in accordance with the Declaration of Helsinki, and the protocol was approved by the departmental review boards and by the Ethics Committee (Parere CEUR-2019-Os-030, Regional Ethics Committee of Friuli Venezia Giulia, Italy).

Informed Consent Statement: Written informed consent was obtained from all subjects involved in the study.

Data Availability Statement: Original data used for this study are available upon request.

Conflicts of Interest: The authors declare no conflict of interest.

\section{References}

1. Bray, F.; Ferlay, J.; Soerjomataram, I.; Siegel, R.L.; Torre, L.A.; Jemal, A. Global Cancer Statistics 2018: GLOBOCAN Estimates of Incidence and Mortality Worldwide for 36 Cancers in 185 Countries. CA Cancer J. Clin. 2018, 68, 394-424. [CrossRef]

2. Araghi, M.; Soerjomataram, I.; Jenkins, M.; Brierley, J.; Morris, E.; Bray, F.; Arnold, M. Global Trends in Colorectal Cancer Mortality: Projections to the Year 2035. Int. J. Cancer 2019, 144, 2992-3000. [CrossRef] [PubMed]

3. Kopetz, S.; Chang, G.J.; Overman, M.J.; Eng, C.; Sargent, D.J.; Larson, D.W.; Grothey, A.; Vauthey, J.-N.; Nagorney, D.M.; McWilliams, R.R. Improved Survival in Metastatic Colorectal Cancer Is Associated with Adoption of Hepatic Resection and Improved Chemotherapy. J. Clin. Oncol. Off. J. Am. Soc. Clin. Oncol. 2009, 27, 3677-3683. [CrossRef] [PubMed]

4. Cremolini, C.; Loupakis, F.; Antoniotti, C.; Lupi, C.; Sensi, E.; Lonardi, S.; Mezi, S.; Tomasello, G.; Ronzoni, M.; Zaniboni, A.; et al. FOLFOXIRI plus Bevacizumab versus FOLFIRI plus Bevacizumab as First-Line Treatment of Patients with Metastatic Colorectal Cancer: Updated Overall Survival and Molecular Subgroup Analyses of the Open-Label, Phase 3 TRIBE Study. Lancet Oncol. 2015, 16, 1306-1315. [CrossRef] 
5. Tabernero, J.; Van Cutsem, E.; Lakomý, R.; Prausová, J.; Ruff, P.; van Hazel, G.A.; Moiseyenko, V.M.; Ferry, D.R.; McKendrick, J.J.; Soussan-Lazard, K.; et al. Aflibercept versus Placebo in Combination with Fluorouracil, Leucovorin and Irinotecan in the Treatment of Previously Treated Metastatic Colorectal Cancer: Prespecified Subgroup Analyses from the VELOUR Trial. Eur. J. Cancer 2014, 50, 320-331. [CrossRef] [PubMed]

6. Schwartzberg, L.S.; Rivera, F.; Karthaus, M.; Fasola, G.; Canon, J.-L.; Hecht, J.R.; Yu, H.; Oliner, K.S.; Go, W.Y. PEAK: A Randomized, Multicenter Phase II Study of Panitumumab Plus Modified Fluorouracil, Leucovorin, and Oxaliplatin (MFOLFOX6) or Bevacizumab Plus MFOLFOX6 in Patients With Previously Untreated, Unresectable, Wild-Type KRAS Exon 2 Metastatic Colorectal. J. Clin. Oncol. 2014, 32, 2240-2247. [CrossRef] [PubMed]

7. Heinemann, V.; von Weikersthal, L.F.; Decker, T.; Kiani, A.; Vehling-Kaiser, U.; Al-Batran, S.-E.; Heintges, T.; Lerchenmüller, C.; Kahl, C.; Seipelt, G.; et al. FOLFIRI plus Cetuximab versus FOLFIRI plus Bevacizumab as First-Line Treatment for Patients with Metastatic Colorectal Cancer (FIRE-3): A Randomised, Open-Label, Phase 3 Trial. Lancet Oncol. 2014, 15, 1065-1075. [CrossRef]

8. Mayer, R.J.; Van Cutsem, E.; Falcone, A.; Yoshino, T.; Garcia-Carbonero, R.; Mizunuma, N.; Yamazaki, K.; Shimada, Y.; Tabernero, J.; Komatsu, Y.; et al. Randomized Trial of TAS-102 for Refractory Metastatic Colorectal Cancer. N. Engl. J. Med. 2015, 372, 1909-1919. [CrossRef]

9. Grothey, A.; Van Cutsem, E.; Sobrero, A.; Siena, S.; Falcone, A.; Ychou, M.; Humblet, Y.; Bouché, O.; Mineur, L.; Barone, C.; et al. Regorafenib Monotherapy for Previously Treated Metastatic Colorectal Cancer (CORRECT): An International, Multicentre, Randomised, Placebo-Controlled, Phase 3 Trial. Lancet 2013, 381, 303-312. [CrossRef]

10. Tournigand, C.; Cervantes, A.; Figer, A.; Lledo, G.; Flesch, M.; Buyse, M.; Mineur, L.; Carola, E.; Etienne, P.-L.; Rivera, F.; et al. OPTIMOX1: A Randomized Study of FOLFOX4 or FOLFOX7 with Oxaliplatin in a Stop-and-Go Fashion in Advanced Colorectal Cancer-A GERCOR Study. J. Clin. Oncol. 2006, 24, 394-400. [CrossRef]

11. de Gramont, A.; Buyse, M.; Abrahantes, J.C.; Burzykowski, T.; Quinaux, E.; Cervantes, A.; Figer, A.; Lledo, G.; Flesch, M.; Mineur, L.; et al. Reintroduction of Oxaliplatin Is Associated with Improved Survival in Advanced Colorectal Cancer. J. Clin. Oncol. 2007, 25, 3224-3229. [CrossRef]

12. Wasan, H.; Meade, A.M.; Adams, R.; Wilson, R.; Pugh, C.; Fisher, D.; Sydes, B.; Madi, A.; Sizer, B.; Lowdell, C.; et al. Intermittent Chemotherapy plus Either Intermittent or Continuous Cetuximab for First-Line Treatment of Patients with KRAS Wild-Type Advanced Colorectal Cancer (COIN-B): A Randomised Phase 2 Trial. Lancet Oncol. 2014, 15, 631-639. [CrossRef]

13. Luo, H.Y.; Li, Y.H.; Wang, W.; Wang, Z.Q.; Yuan, X.; Ma, D.; Wang, F.H.; Zhang, D.S.; Lin, D.R.; Lin, Y.C.; et al. Single-Agent Capecitabine as Maintenance Therapy after Induction of XELOX (or FOLFOX) in First-Line Treatment of Metastatic Colorectal Cancer: Randomized Clinical Trial of Efficacy and Safety. Ann. Oncol. 2016, 27, 1074-1081. [CrossRef]

14. Cremolini, C.; Antoniotti, C.; Lonardi, S.; Aprile, G.; Bergamo, F.; Masi, G.; Grande, R.; Tonini, G.; Mescoli, C.; Cardellino, G.G.; et al. Activity and Safety of Cetuximab Plus Modified FOLFOXIRI Followed by Maintenance With Cetuximab or Bevacizumab for RAS and BRAF Wild-Type Metastatic Colorectal Cancer: A Randomized Phase 2 Clinical Trial. JAMA Oncol. 2018, 4, 529-536. [CrossRef] [PubMed]

15. Stein, A.; Schwenke, C.; Folprecht, G.; Arnold, D. Effect of Application and Intensity of Bevacizumab-Based Maintenance after Induction Chemotherapy with Bevacizumab for Metastatic Colorectal Cancer: A Meta-Analysis. Clin. Colorectal Cancer 2016, 15, e29-e39. [CrossRef] [PubMed]

16. Hegewisch-Becker, S.; Graeven, U.; Lerchenmüller, C.A.; Killing, B.; Depenbusch, R.; Steffens, C.C.; Al-Batran, S.E.; Lange, T.; Dietrich, G.; Stoehlmacher, J.; et al. Maintenance Strategies after First-Line Oxaliplatin plus Fluoropyrimidine plus Bevacizumab for Patients with Metastatic Colorectal Cancer (AIO 0207): A Randomised, Non-Inferiority, Open-Label, Phase 3 Trial. Lancet Oncol. 2015, 16, 1355-1369. [CrossRef]

17. Díaz-Rubio, E.; Gómez-España, A.; Massutí, B.; Sastre, J.; Abad, A.; Valladares, M.; Rivera, F.; Safont, M.J.; Martínez de Prado, P.; Gallén, M.; et al. First-Line XELOX plus Bevacizumab Followed by XELOX plus Bevacizumab or Single-Agent Bevacizumab as Maintenance Therapy in Patients with Metastatic Colorectal Cancer: The Phase III MACRO TTD Study. Oncologist 2012, 17, 15-25. [CrossRef] [PubMed]

18. Pietrantonio, F.; Morano, F.; Corallo, S.; Miceli, R.; Lonardi, S.; Raimondi, A.; Cremolini, C.; Rimassa, L.; Bergamo, F.; SartoreBianchi, A.; et al. Maintenance Therapy with Panitumumab Alone vs. Panitumumab Plus Fluorouracil-Leucovorin in Patients with RAS Wild-Type Metastatic Colorectal Cancer: A Phase 2 Randomized Clinical Trial. JAMA Oncol. 2019, 5, 1268-1275. [CrossRef] [PubMed]

19. Aparicio, T.; Ghiringhelli, F.; Boige, V.; Le Malicot, K.; Taieb, J.; Bouche, O.; Phelip, J.M.; François, E.; Borel, C.; Faroux, R.; et al. Bevacizumab Maintenance versus No Maintenance during Chemotherapy-Free Intervals in Metastatic Colorectal Cancer: A Randomized Phase III Trial (PRODIGE 9). J. Clin. Oncol. 2018, 36, 674-681. [CrossRef]

20. Koeberle, D.; Betticher, D.C.; von Moos, R.; Dietrich, D.; Brauchli, P.; Baertschi, D.; Matter, K.; Winterhalder, R.; Borner, M.; Anchisi, S.; et al. Bevacizumab Continuation versus No Continuation after First-Line Chemotherapy plus Bevacizumab in Patients with Metastatic Colorectal Cancer: A Randomized Phase III Non-Inferiority Trial (SAKK 41/06). Ann. Oncol. 2015, 26, 709-714. [CrossRef]

21. Chibaudel, B.; Maindrault-Goebel, F.; Lledo, G.; Mineur, L.; André, T.; Bennamoun, M.; Mabro, M.; Artru, P.; Carola, E.; Flesch, M.; et al. Can Chemotherapy Be Discontinued in Unresectable Metastatic Colorectal Cancer? The GERCOR OPTIMOX2 Study. J. Clin. Oncol. 2009, 27, 5727-5733. [CrossRef] 
22. Simkens, L.H.J.; Van Tinteren, H.; May, A.; Ten Tije, A.J.; Creemers, G.J.M.; Loosveld, O.J.L.; De Jongh, F.E.; Erdkamp, F.L.G.; Erjavec, Z.; Van Der Torren, A.M.E.; et al. Maintenance Treatment with Capecitabine and Bevacizumab in Metastatic Colorectal Cancer (CAIRO3): A Phase 3 Randomised Controlled Trial of the Dutch Colorectal Cancer Group. Lancet 2015, 385, $1843-1852$. [CrossRef]

23. Cremolini, C.; Casagrande, M.; Loupakis, F.; Aprile, G.; Bergamo, F.; Masi, G.; Moretto, R.R.; Pietrantonio, F.; Marmorino, F.; Zucchelli, G.; et al. Efficacy of FOLFOXIRI plus Bevacizumab in Liver-Limited Metastatic Colorectal Cancer: A Pooled Analysis of Clinical Studies by Gruppo Oncologico Del Nord Ovest. Eur. J. Cancer 2017, 73, 74-84. [CrossRef] [PubMed]

24. Modest, D.P.; Martens, U.M.; Riera-Knorrenschild, J.; Greeve, J.; Florschütz, A.; Wessendorf, S.; Ettrich, T.; Kanzler, S.; Nörenberg, D.; Ricke, J.; et al. FOLFOXIRI Plus Panitumumab As First-Line Treatment of RAS Wild-Type Metastatic Colorectal Cancer: The Randomized, Open-Label, Phase II VOLFI Study (AIO KRK0109). J. Clin. Oncol. 2019, 37, 3401-3411. [CrossRef]

25. Van Cutsem, E.; Cervantes, A.; Adam, R.; Sobrero, A.; Van Krieken, J.H.; Aderka, D.; Aranda Aguilar, E.; Bardelli, A.; Benson, A.; Bodoky, G.; et al. ESMO Consensus Guidelines for the Management of Patients with Metastatic Colorectal Cancer. Ann. Oncol. Off. J. Eur. Soc. Med. Oncol. 2016, 27, 1386-1422. [CrossRef]

26. Garattini, S.K.; Bonotto, M.; Porcu, L.; Ongaro, E.; Gerratana, L.; Basile, D.; Parnofiello, A.; Pelizzari, G.; Cortiula, F.; Corvaja, C.; et al. Determinants of Choice in Offering Drug Holidays during First-Line Therapy for Metastatic Colorectal Cancer. Future Oncol. Lond. Engl. 2020, 16, 2645-2660. [CrossRef]

27. Maughan, T.S.; James, R.D.; Kerr, D.J.; Ledermann, J.A.; Seymour, M.T.; Topham, C.; McArdle, C.; Cain, D.; Stephens, R.J. Comparison of Intermittent and Continuous Palliative Chemotherapy for Advanced Colorectal Cancer: A Multicentre Randomised Trial. Lancet 2003, 361, 457-464. [CrossRef]

28. Labianca, R.; Sobrero, A.; Isa, L.; Cortesi, E.; Barni, S.; Nicolella, D.; Aglietta, M.; Lonardi, S.; Corsi, D.; Turci, D.; et al. Intermittent versus Continuous Chemotherapy in Advanced Colorectal Cancer: A Randomised "GISCAD" Trial. Ann. Oncol. Off. J. Eur. Soc. Med. Oncol. 2011, 22, 1236-1242. [CrossRef] [PubMed]

29. Adams, R.A.; Meade, A.M.; Seymour, M.T.; Wilson, R.H.; Madi, A.; Fisher, D.; Kenny, S.L.; Kay, E.; Hodgkinson, E.; Pope, M.; et al. Intermittent versus Continuous Oxaliplatin and Fluoropyrimidine Combination Chemotherapy for First-Line Treatment of Advanced Colorectal Cancer: Results of the Randomised Phase 3 MRC COIN Trial. Lancet Oncol. 2011, 12, 642-653. [CrossRef]

30. Maindrault-Goebel, F.; Lledo, G.; Chibaudel, B.; Mineur, L.; Andre, T.; Bennamoun, M.; Mabro, M.; Artru, P.; Louvet, C.; De Gramont, A. OPTIMOX2, a Large Randomized Phase II Study of Maintenance Therapy or Chemotherapy-Free Intervals (CFI) after FOLFOX in Patients with Metastatic Colorectal Cancer (MRC). A GERCOR Study. J. Clin. Oncol. 2006, 24, 3504. [CrossRef]

31. Berry, S.R.; Cosby, R.; Asmis, T.; Chan, K.; Hammad, N.; Krzyzanowska, M.K. Cancer Care Ontario's Gastrointestinal Disease Site Group Continuous versus Intermittent Chemotherapy Strategies in Metastatic Colorectal Cancer: A Systematic Review and Meta-Analysis. Ann. Oncol. Off. J. Eur. Soc. Med. Oncol. 2015, 26, 477-485. [CrossRef] [PubMed]

32. Loree, J.M.; Tan, S.K.; Lafond, L.M.; Speers, C.H.; Kennecke, H.F.; Cheung, W.Y. Real-World Effect of Maintenance and Intermittent Chemotherapy on Survival in Metastatic Colorectal Cancer. Clin. Colorectal Cancer 2018, 17, 65-72. [CrossRef] [PubMed]

33. Bahrabadi, A.; Ruan, J.; Gresham, G.; Cheung, W.Y. Predictors of Treatment Attrition in Patients with Metastatic Colorectal Cancer (mCRC). J. Clin. Oncol. 2017, 35, e18041. [CrossRef]

34. Peduzzi, P.; Concato, J.; Feinstein, A.R.; Holford, T.R. Importance of Events per Independent Variable in Proportional Hazards Regression Analysis. II. Accuracy and Precision of Regression Estimates. J. Clin. Epidemiol. 1995, 48, 1503-1510. [CrossRef] 